\title{
Condition Assessment of Power Transformers Using Loss Tangent Measurements
}

\author{
M.A.R.M. Fernando
}

\begin{abstract}
Mineral oil, cellulose paper and pressboard are the main insulation materials in a power transformer. During service, increase of moisture, as the by-products ageing and increases the risk of insulation failure. This paper presents the possibility to use loss tangent (or power factor) and capacitance ( $\tan \delta$ and C) measurements as an estimate of the 'wetness' of aged transformer insulation. Firstly oil, paper and pressboard samples were aged under laboratory conditions and their tan $\delta$ and dielectric constant ( $\varepsilon r$ ) values were measured. Applying the tan $\delta$ and $\varepsilon r$ obtained onto a transformer insulation model, the tan $\delta$ and $\mathrm{C}$ of transformer were calculated and the effects of insulation geometry, moisture content $(\mathrm{MC})$ of pressboard, oil conductivity $\left(\sigma_{\text {oil }}\right)$ and insulation temperature under test were established. It was found that $\tan \delta$ and $C$ values of a transformer strongly depended on its insulation geometry and the temperature. If the temperature is fixed, the change of tan $\delta$ value of a transformer can be a direct measure of moisture in pressboard for 'wet' and 'extremely wet' conditions. For a 'dry' transformer, the $\sigma_{\text {oil }}$ oil value is needed as an additional known parameter in order to estimate accurately the moisture in pressboard.
\end{abstract}

Key words: Power transformer, ageing, moisture, loss factor, capacitance

\section{Introduction}

Power transformers are considered as one of the most vital and costly apparatus in power system networks. The usual 'design life' of a power transformer is expected to be $25-40$ years. However, relying on condition assessment and residual life estimation, the utilities are keen on continuously operating the transformers over their designed lifetime without reliability and safety being compromised. Power transformers usually have insulation systems which consist of oil, paper and pressboard, and the deterioration of the insulation is one of the main factor to determine the lifespan of the transformer. Temperature, moisture and oxygen are the main ageing factors. Moisture in particular, is the main cause for weakening cellulose solid insulation and shortening the lifetime of transformer. It is suggested that the moisture content should be maintained below $2.0 \%$ in the paper insulation in order to provide good electrical and mechanical strength for a transformer to have a longer lifetime [1].

Tests are commonly used today [2-4] to assess the "wetness" condition of transformer insulation. As an example, oil samples are taken regularly to laboratory for measuring the moisture content in oil, and indirect estimation on moisture content in paper/pressboard insulation can then be achieved using moisture equilibrium curves $[5,6]$. In the field, electrical tests carried out during regular maintenance/ test period also provide information about the "wetness" of transformer insulation. Out of different electrical tests, attention has recently been paid on frequency domain spectroscopy (FDS) due to its noise effectiveness over the time domain measurements $[7,8]$. FDS measures $\tan \delta$ or complex capacitance in the frequency range between $1 \mathrm{mHz}$ to $1 \mathrm{kHz}$. Since the most prominent information about the moisture is mainly available at low frequencies, completion of one FDS measurement usually takes several hours out of the regular maintenance period of the transformer if the test is extended to below $1 \mathrm{mHz}$. While the transformer is being tested in the field, it naturally cools down. The continuous temperature reduction could cause water diffusions as well as change of spectrum. These changes in transformer insulation affect on the FDS results due to long testing time.

On the other hand, the loss tangent and capacitance ( $\tan \delta$ and C) measurements at $50 \mathrm{~Hz}$,

Eng. (Dr.) M.A.R.M Fernando, C. Eng., MIE(Sri Lanka), MIEEE, MSLAAS, MSLEMA, B.SC. Eng. (Hons) (Peradeniya), Tech Lic. (KTH), PhD. (Chaimers)

Senior Lecturer, Department of Electrical \& Electronic Engineering, University of Peradeniya. At present, he is the chair of IEEE Sri Lanka Central Region Subsection. 
are commonly used by utilities as a diagnostic tool [9] and it is much less time consuming. Most importantly, some of the old transformers operating in the network normally do not have a complete set of $\tan \delta$ and $C$ test record since their very first factory test. Sometimes the details related to their geometry are also missing. However, estimation of moisture content (MC) in transformers can be achieved through a comparative approach once the relationship between the MC and $\tan \delta$ is established. This work aims to use $\tan \delta$ measurements as a MC assessment tool for transformer insulation. This is based on the understanding on how $\tan \delta$ is affected by various parameters such as MC of paper/pressboard, geometry of the insulation, conductivity of oil, and the temperature inside the transformer. First, the basic relationships between MCs of individual oil, paper and pressboard with $\tan \delta$ were established using laboratory tests. Second, the combined oil/ paper/pressboard insulation was modelled using the obtained results from laboratory measurements in order to correlate $\tan \delta$ with those affecting factors.

\section{Power Transformer Insulation}

A power transformer consists of main windings (LV and HV) and core. The windings are covered with paper insulation whereas the main insulation between LV and HV windings are oil and pressboard. Figure 1a shows a cross sectional view of a transformer. The oil/ pressboard insulation consists of multiple oil ducts separated by cylindrical pressboard bàrriers and supported by spacers. The cross sectional view of Figure 1(a) for the main insulation is shown in Figure 1(b). Despite the windings are being cylindrical in shape the radius of $\mathrm{LV}$ winding is sufficiently large to assume the combined oil/paper/pressboard insulation as series/parallel plate capacitors. The same materials, pressboard, paper and oil ducts can be put together and the well known "X-Y model" for transformer insulation can be formed [10]. Here, when comparing oil and pressboard insulation, the current through oil has a considerable effect from its conductivity and negligible polarization effect compared to those in pressboard. Thus the current flow through series oil-pressboard barriers and axial pressboard spacers are nearly independent so that they can be treated separately. By lumping separately the distributed series oil-pressboard barriers and pressboard spacers together the insulation can be simplified to a composite model [10] as shown in Figure 1(c). By considering the width and the periphery of the insulation as unity, the parameters $t, X$ and $Y$ can be taken as

$t=$ The ratio between the inter-turn paper thickness to the radial width of the main insulation

$X=$ The ratio between the total thickness of pressboard barriers to the radial width of the main insulation

$Y=$ The ratio between the total width of spacers to the average perimeter of the main insulation

$X$ and $Y$ parameters vary with the configuration and construction of the transformer. Between $\mathrm{HV}$ and LV windings, the typical values for $X$ and $Y$ are $\sim 20 \%$ and $\sim 25 \%$. Between the LV winding and ground (core) the typical values for $X=\sim 50 \%$ and $Y=\sim 25 \%$. Between HV winding and ground (tank) $X$ is very small and $Y$ is almost negligible [11].

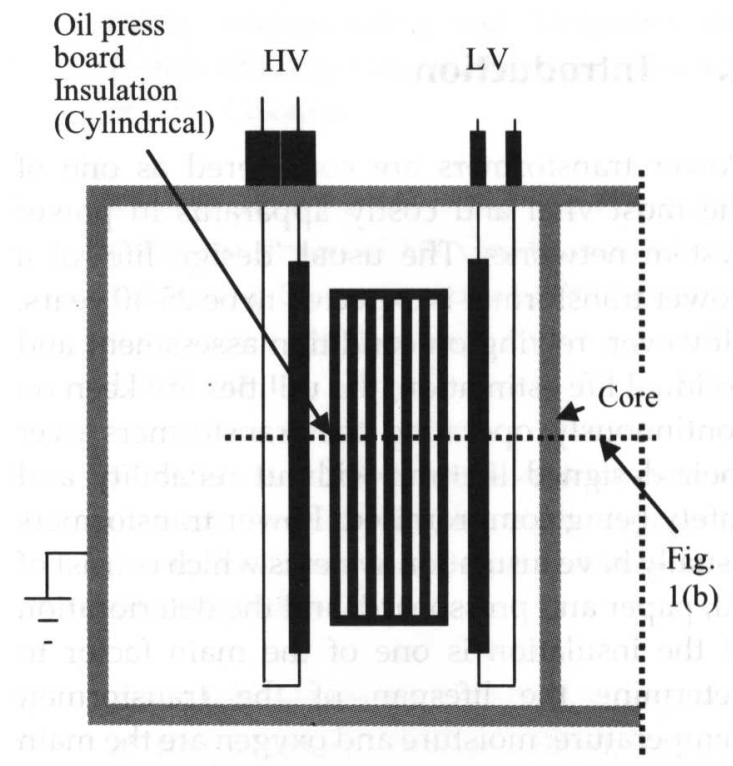

Figure 1(a) - Cross section view of transformer

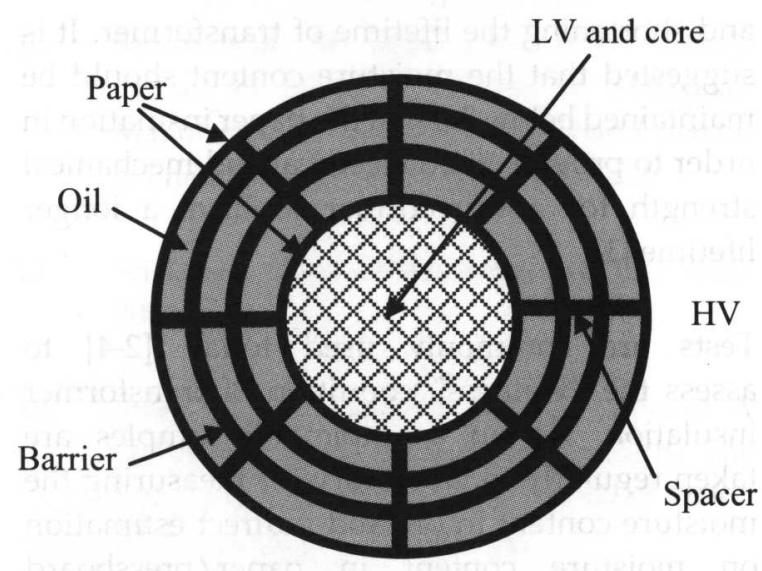

Figure 1(b) - Insulation between LV and HV windings 


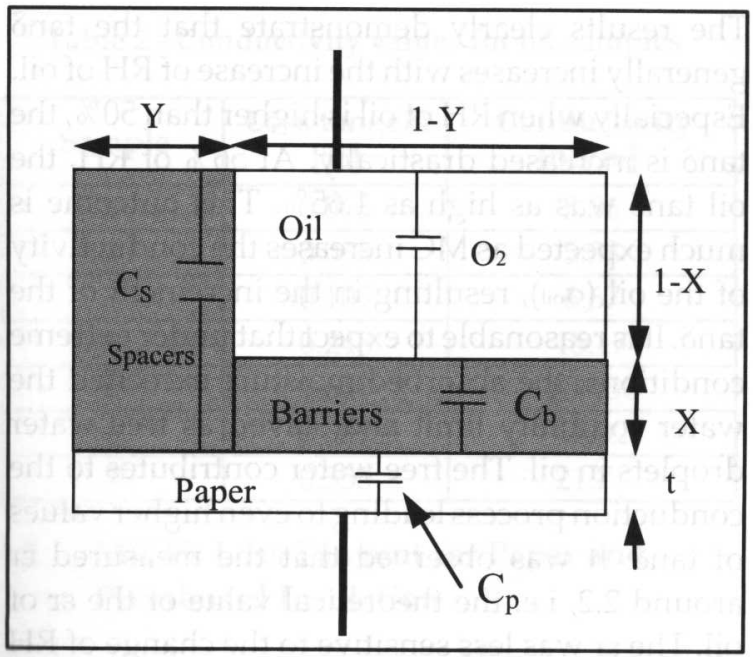

Figure 1(c) - Transformer paper/pressboard/oil insulation model between $\mathrm{HV}$ and $\mathrm{LV}$ windings as in X-Y Model [10]

\section{Laboratory Measurements}

\subsection{Oil samples}

Six oil samples (NYTRO-10-GBN insulating oil) were prepared for the study. Out of them four samples were used to check the moisture effect by varying the relative humidity $(\mathrm{RH})$ condition. The rest of the samples were aged under laboratory conditions. In comparison a virgin oil sample was also used. The details of the samples are given below.

$\begin{array}{ll}\text { Sample 1 } & \text { Virgin }(700 \mathrm{ml}) \\ \text { Sample 2 } & \text { Non-aged at RH } 11.3 \%(700 \mathrm{ml}) \\ \text { Sample 3 } & \text { Non-aged at RH } 32.4 \%(700 \mathrm{ml}) \\ \text { Sample 4 } & \text { Non-aged at RH } 48.7 \%(700 \mathrm{ml}) \\ \text { Sample 5 } & \text { Non-aged at RH } 56.0 \%(700 \mathrm{ml}) \\ \text { Sample 6 } & \text { Aged under sealed condition } \\ & \left(1000 \mathrm{ml} \text { at } 115^{\circ} \mathrm{C} \text { for } 21 \text { days }\right)\end{array}$

Sample 7 Aged under unsealed condition (500 $\mathrm{ml}$ at $115^{\circ} \mathrm{C}$ for 56 days)

For humidity treatment, the samples were conditioned in a desiccator at room temperature for about one week. The air RH of the desiccator was controlled by mixing different portions of glycerol and distilled water and the mixture was prepared and put in the dessicator for two hours beforehand to ensure it reached the equilibrium state before trays of mineral oil were put inside. The values of the $\mathrm{RH}$ were verified by a hygrometer inside the dessicator. The samples 6 and 7 were aged under sealed and unsealed condition in an air-circulating oven (inner size:
$490 \times 430 \times 610 \mathrm{~mm} 3)$. The two different methods i.e. sealed and unseal, were used in order to simulate hermetically sealed transformer and free breathing transformer during ageing process.

After preparation of oil samples, the MCs levels were determined by Karl Fischer Titration method using Metrohm 684 Coulometer and 832 Thermoprep. Each sample was tested three times and the average value was obtained. Afterwards the $\tan \delta$ and $\varepsilon \mathrm{r}$ values were measured on samples using ELTEL ADTR-2K. Three measurements were taken for each sample inside an oil test cell which has the geometric capacitance value of $\sim 70 \mathrm{pF}$ and the test voltage was $2.0 \mathrm{kV}$. New virgin mineral oil was used to wash the test cell in between different measurements. The average value of the $\tan \delta$ was used for the evaluation.

\subsection{Paper samples}

Two oil-free non-aged paper samples with the size of $150 \mathrm{~mm} \times 160 \mathrm{~mm}$ and the thickness of $0.25 \mathrm{~mm}$ were used for the study. Each sample was separately impregnated under dry and wet conditions. The dry samples were first dried in the air-circulating oven at $1050 \mathrm{C}$ for 24 hours and were further dried in a vacuum oven at 1050C, 7.5 mbar for 24 hours. At the same time, mineral oil was put into the vacuum oven for degassing and dehydration. Finally, the samples were immersed into the pre-processed mineral oil for impregnation and kept for 48 hours. The wet samples were conditioned by exposing them to atmosphere at room temperature and $\mathrm{RH}$ of $50 \%$ for 48 hours and were immersed into preprocessed mineral oil for impregnation under vacuum for 72 hours.

The $\tan \delta$ and $\varepsilon \mathrm{r}$ measurements were taken on each paper samples using ADTR-2K at room temperature of $20^{\circ} \mathrm{C}$. The test sample was kept between upper and lower cylindrical electrodes of a three-terminal guarded solid test cell where the high voltage was supplied to the lower electrode. The diameters of the upper and lower electrodes were $100 \mathrm{~mm}$ and $150 \mathrm{~mm}$ respectively and the upper electrode was surrounded by a guarded ring of $10 \mathrm{~mm}$ in thickness. The cell capacitance varied with the thickness of the samples and it was approximately $70 \mathrm{pF}$ for a $1 \mathrm{~mm}$ gap. The solid test cell was kept inside the desiccator under controlled humidity of $21 \%$ (approximately half of the air $\mathrm{RH}$ of the environment) using silica gel. The measurements 
were repeated for three times for each sample and the average value was taken. The MCs of the samples (before the test) were measured using Karl Fischer Titration method.

Additional $\tan \delta$ measurements were taken on wet sample with different MC levels. First, the wet sample soaked in mineral oil were heated in the air circulating oven for two hours at $80^{\circ} \mathrm{C}$ to allow evaporating some of the moisture inside it in order to get different MC levels. Then the measurements of $\tan \delta$ and MC were recorded two times at room temperature of $20^{\circ} \mathrm{C}$.

\subsection{Pressboard samples}

Four oil-free non-aged pressboard samples with the size of $150 \mathrm{~mm} \times 160 \mathrm{~mm}$ and the thicknesses of $1.5 \mathrm{~mm}$ and $3 \mathrm{~mm}$ for two each, were used for the study.

The four pressboard samples were divided into two sample sets of thickness 1.5 and $3 \mathrm{~mm}$ each. The samples were impregnated under dry and wet conditions similar to paper samples. The $\tan \delta$ and $\varepsilon r$ measurements were taken on each pressboard samples. For wet pressboard samples, only one measurement was taken after the heat treatment.

\section{Results of Laboratory Measurements}

\subsection{Conductivity Vs Loss Tangent for Oil Insulation}

Table 1 shows the loss tangent and MCs of oil samples. For non-aged samples the $\mathrm{RH}$ values are included.

Table 1 - Results of relative humidity, MCs and loss tangents for oil samples

\begin{tabular}{|c|c|c|c|}
\hline $\begin{array}{c}\text { Sample } \\
\text { No }\end{array}$ & $\begin{array}{c}\text { Moisture } \\
\text { content } \\
{[\mathrm{ppm}]}\end{array}$ & $\begin{array}{c}\text { Relative } \\
\text { humidity } \\
{[\%]}\end{array}$ & $\begin{array}{c}\text { Loss } \\
\text { tangent } \\
{[\%]}\end{array}$ \\
\hline 1 & 10.1 & & 0.063 \\
\hline 2 & 6.2 & 11.3 & 0.088 \\
\hline 3 & 17.8 & 32.4 & 0.109 \\
\hline 4 & 26.8 & 48.7 & 0.248 \\
\hline 5 & 30.8 & 56.0 & 1.649 \\
\hline 6 & & Sealed (7 days) & 0.161 \\
\cline { 2 - 4 } & 34.5 & (21 days) & 0.687 \\
\hline \multirow{2}{*}{7} & & Unsealed (7 ds) & 0.151 \\
\cline { 2 - 4 } & & (21 days) & 0.210 \\
\cline { 2 - 4 } & 27.9 & (56 days) & 0.355 \\
\hline
\end{tabular}

The results clearly demonstrate that the $\tan \delta$ generally increases with the increase of $\mathrm{RH}$ of oil. Especially when RH of oil is higher than $50 \%$, the $\tan \delta$ is increased drastically. At $56 \%$ of $\mathrm{RH}$, the oil $\tan \delta$ was as high as $1.65 \%$. This outcome is much expected as MC increases the conductivity of the oil $\left(\sigma_{\text {oil }}\right)$, resulting in the increment of the $\tan \delta$. It is reasonable to expect that under extreme conditions, the absorbed moisture exceeded the water solubility limit and stayed as free water droplets in oil. The free water contributes to the conduction process leading to even higher values of $\tan \delta$. It was observed that the measured $\varepsilon \mathrm{r}$ around 2.2, i.e. the theoretical value of the $\varepsilon \mathrm{r}$ of oil. The $\varepsilon r$ was less sensitive to the change of $\mathrm{RH}$ of the mineral oil. It is supposed that the amount of moisture containing in the oil is too small to influence the $\varepsilon r$. Although the $\mathrm{RH}$ between each sample increased by at least $7 \%$, yet from a different perspective, the $\mathrm{MC}$ is in the range of parts per million (ppm), and in these samples may differ by the most about 25 ppm, which is too little to make any influence to the $\varepsilon$.

During ageing the $\tan \delta$ increased with ageing. It is clearly stated that the produced moisture and other ageing by-products increased the $\tan \delta$ values for both sealed and unsealed conditions. The $\tan \delta$ values for sealed and unsealed conditions with respect to time were similar up to 7 days and then later were significantly lower for unsealed samples than that of sealed samples. The ageing under unsealed conditions allowed free evaporating moisture and by-products from the oil samples so that the measured $\tan \delta$ and $\mathrm{MC}$ values were lower. On the other hand, under sealed condition, with sufficient amount of free air inside the sealed container (about $500 \mathrm{ml}$ out of $1000 \mathrm{ml}$ ), the oxidization and hydrolysis actions took place increasing the losses and moisture.

Since the conductivity represents the effect of both moisture and other conductive byproducts rather than $\mathrm{MC}$, it was used for further investigations. The $\sigma_{\text {oil }}$ can be calculated using measured loss tangents as

$\sigma_{\text {oil }}=\omega \varepsilon_{0} \varepsilon_{r} \tan \delta$

At $50 \mathrm{~Hz}, \varepsilon \mathrm{r}=2.2$, and $\varepsilon_{0}=8.85 \times 10^{-12}$. Table 2 shows the calculated conductivities (at $20^{\circ} \mathrm{C}$ ). The measured loss tangent values are included for comparison. 
Table 2 - Conductivity values for oil samples

\begin{tabular}{|c|c|c|}
\hline Sample & $\begin{array}{c}\text { Loss tangent } \\
{[\%]}\end{array}$ & $\begin{array}{c}\text { Conductivity } \\
{[\mathrm{pS} / \mathrm{m}]}\end{array}$ \\
\hline 1 & 0.063 & 3.86 \\
\hline 2 & 0.088 & 5.38 \\
\hline 3 & 0.109 & 6.67 \\
\hline 4 & 0.248 & 15.17 \\
\hline 5 & 1.649 & 100.86 \\
\hline 6 & 0.687 & 42.02 \\
\hline 7 & 0.355 & 21.71 \\
\hline
\end{tabular}

\subsection{Vs Loss Tangent for Paper and Pressboard Insulation}

Table 3 shows the variation of $\tan \delta$ values for paper and pressboard samples with different treatments. Figure 2 shows the variations of $\tan \delta$ and $\varepsilon r$ values for paper and pressboard samples with different $\mathrm{MC}$ levels. The trend lines for the scattering of data points are also included.

It could be clearly observed that the $\tan \delta$ and $\varepsilon r$ values increase with MC values. In the former case, the variation of $\tan \delta$ is significant as exponential whereas for the latter case the $\mathrm{r}$ values double for wet pressboard samples. Water is much more polar as compared with cellulose, and therefore MC increases conductivity of paper and pressboard and subsequently increases the $\tan \delta$. Similarly, higher $\varepsilon r$ of moisture than that of cellulose contributes towards the increase of $\mathrm{er}$ value of the wetted samples.

Table 3 - MCs and loss tangent values for paper and pressboard samples

\begin{tabular}{|c|c|c|}
\hline Treatment & $\mathrm{MC}[\%]$ & $\tan \delta[\%]$ \\
\hline \multicolumn{3}{|c|}{ Paper samples $[0.25 \mathrm{~mm}]$} \\
\hline Dry & 0.718 & 2.4 \\
\hline Wet & 1.426 & 33.8 \\
\hline 2 hrs heating & 0.949 & 19.9 \\
\hline 4 hrs heating & 0.737 & 7.5 \\
\hline \multicolumn{3}{|c|}{ Pressboard samples $[1.5 \mathrm{~mm}]$} \\
\hline Dry & 1.091 & 0.663 \\
\hline Wet & 5.455 & 57.0 \\
\hline 2 hrs heating & 3.595 & 48.6 \\
\hline \multicolumn{3}{|c|}{ Pressboard samples [3 mm] } \\
\hline Dry & 1.518 & 0.70 \\
\hline Wet & 6.511 & 70.0 \\
\hline 2 hrs heating & 5.254 & 57.0 \\
\hline
\end{tabular}

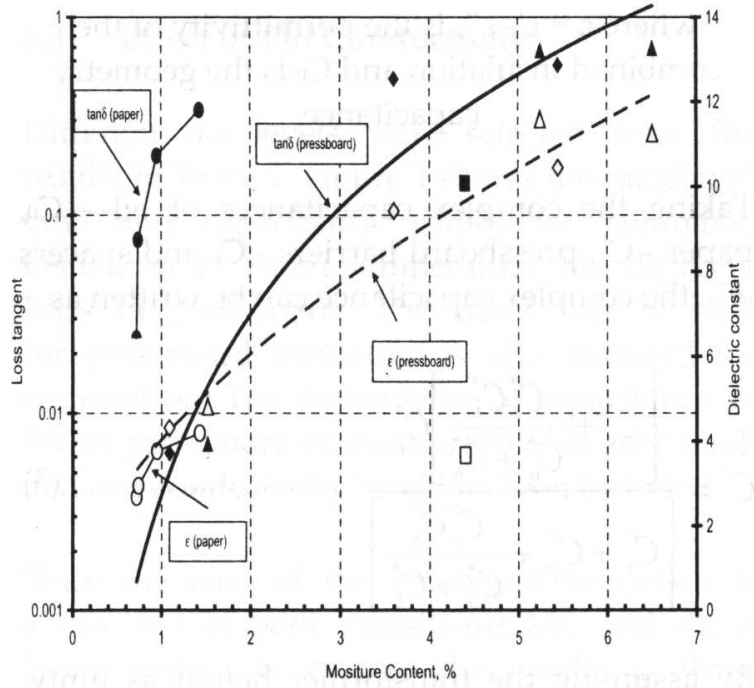

Figure 2 - Loss tangent and dielectric constant of paper $(0.25 \mathrm{~mm})$ and pressboard $(1.5 \mathrm{~mm} \& 3.0 \mathrm{~mm})$ samples as a function of the MC.

$\bullet \tan \delta$ for $1.5, \diamond \varepsilon \mathrm{r}$ for $1.5, \boldsymbol{\Delta} \tan \delta$ for 3.0,

$\triangle \varepsilon r$ for 3.0, tano for $0.25, \mathrm{O} \varepsilon \mathrm{r}$ for 0.25 ,

The $\tan \delta$ value is expected to be geometry independent. However, higher levels of $\tan \delta$ values could be seen for paper than pressboard samples at the same level of MC. This is due to the structural difference between paper and pressboard. The oil/cellulose volume ratio in paper almost doubles that in pressboard, and therefore the same level of MC in paper would means a higher percentage of moist cellulose in paper than in pressboard and the tan $\delta$ of paper with the same level of MC is therefore much higher.

\section{Modelling of Transformer Insulation}

The information on $\tan \delta$ versus $\mathrm{MC} / \sigma$ of individual oil, paper and pressboard insulations were used to model the combined oil/paper/ pressboard insulation of a transformer. According to Figure 1(c), the oil and pressboard barriers act as series capacitors. Since the total width of oil ducts is much thicker than that of pressboard, the oil capacitance is much smaller and therefore is dominating. The combined oil/barrier and spacer/barrier act as parallel capacitors and both contribute significantly towards the measured capacitance of transformer. The complex capacitance of the combined oil/paper/pressboard transformer insulation can be written as

$$
C^{*}=C_{0}\left[\varepsilon^{\prime}-j \varepsilon^{\prime \prime}\right]
$$


where $\varepsilon=\varepsilon^{\prime}-\varepsilon^{\prime \prime}$, is the permittivity of the combined insulation and $\mathrm{C}_{0}$ is the geometry capacitance.

Taking the complex capacitances of oil - $\mathrm{C}_{0}$, paper $-C_{p}$, pressboard barriers - $C_{b}$ and spacers -Cs, the complex capacitance can be written as

$$
C^{*}=\frac{\left[C_{s}^{*}+\frac{C_{o}^{*} C_{b}^{*}}{C_{o}^{*}+C_{b}^{*}}\right] C_{p}^{*}}{\left[C_{s}^{*}+C_{p}^{*}+\frac{C_{o}^{*} C_{b}^{*}}{C_{o}^{*}+C_{b}^{*}}\right]}
$$

By assuming the transformer height as unity, the individual complex capacitances of oil ( $\left.\mathrm{C}_{0}\right)$, paper $\left(C_{p}\right)$, pressboard barriers $\left(C_{b}\right)$ and spacers (Cs) can be written as (4)-(7).

$$
\begin{aligned}
& \dot{C}_{o}^{*}=\frac{\varepsilon_{0}(1-Y)}{(1-X)}\left(\varepsilon_{o}^{\prime}-j \varepsilon_{o}^{\prime \prime}\right) \\
& C_{p}^{*}=\frac{\varepsilon_{0}}{t}\left(\varepsilon_{p}^{\prime}-j \varepsilon_{p}^{\prime \prime}\right) \\
& C_{b}^{*}=\frac{\varepsilon_{0}(1-Y)}{X}\left(\varepsilon_{b}^{\prime}-j \varepsilon_{b}^{\prime \prime}\right) \\
& C_{s}^{*}=\varepsilon_{0} Y\left(\varepsilon_{s}^{\prime}-j \varepsilon_{s}^{\prime \prime}\right)
\end{aligned}
$$

The real part of permittivity $\left(\varepsilon^{\prime}\right)$ represents the relative permittivity, $\varepsilon$ r of the material whereas the imaginary part $\left(\varepsilon^{\prime \prime}\right)$ provides the information about the losses in each insulation. The measurable $\tan \delta$ of the combined transformer insulation can be calculated by (2) as

$\tan \delta=\frac{\varepsilon^{\prime \prime}}{\varepsilon^{\prime}}$

The measurable capacitance of the combined transformer insulation is $\mathrm{C}_{0 \varepsilon}^{\prime}$ where geometric capacitance $\mathrm{C}_{0}$ is considered as unity. In order to model the $\tan \delta$ and capacitance the information on individual material, oil (4), paper (5) and pressboard (6\&7) were extracted from laboratory measurements described in section 4 .

In order to model the transformer insulation, the relationships among $\mathrm{MC}$, $\tan \delta$ and $\varepsilon r$ values for paper and pressboard samples were extracted from laboratory results. The selected MC levels were $0.5 \%, 1 \%, 2 \%, 3 \%, 4 \%$ and $5 \%$ which covered dry $(0-2 \%)$, wet $(2-4 \%)$ and extremely wet $(>4.5 \%)$ insulation conditions according to [1]. The extracted results are shown in Table 4 . The $\tan \delta$ and capacitance of combined insulation was estimated using equations (2)-(8) and different effects due to insulation geometry, moisture, $\sigma_{\text {oil }}$ and the temperature were separately studied.

Table 4 - Estimated $\tan \delta$ and $\varepsilon r$ values for paper and pressboard samples

\begin{tabular}{ccccc}
\hline Moisture & \multicolumn{2}{c}{ Pressboard } & \multicolumn{2}{c}{ Paper } \\
\cline { 2 - 5 } content [\%] & Tan $\delta$ & $\varepsilon_{\mathrm{r}}$ & Tan $\delta$ & $\varepsilon_{\mathrm{r}}$ \\
\hline 0.5 & 0.0005 & 4.3 & & \\
1.0 & 0.004 & 4.3 & 0.024 & 2.7 \\
2.0 & 0.03 & 6.0 & & \\
\hline 3.0 & 0.11 & 7.7 & 0.34 & 4.2 \\
4.0 & 0.24 & 9.1 & & \\
\hline 5.0 & 0.50 & 10.4 & 0.34 & 4.2 \\
\hline
\end{tabular}

\subsection{Effect of Insulation Geometry}

Four different insulation geometry cases were considered to represent different practical $\mathrm{X}$ and values between $\mathrm{LV}$ and $\mathrm{HV}$ windings. They were (i) $X=20 \%,=25 \%$, (2) $X=20 \%,=15 \%$, (3) $X=30 \%,=25 \%$, and (4) $X=30 \%, Y=15 \%$. The paper thickness was taken as $2 \%$. Figures $3 a$ and 3 b show the normalized capacitance and $\tan \delta$ versus pressboard MC under different $X$, values.

It is clear that $\tan \delta$ and capacitance increase with the increase of, as an example, the capacitance of transformer increases $21 \%$ at extremely wet conditions ( $\mathrm{MC}=5 \%$ ) when $\mathrm{Y}$ changed from $15 \%$ to $25 \%$. However, if the transformer is under dry insulation condition the difference due to the change of insulation geometry is very low. On the other hand, variation of capacitance due to increase of $X$ seems to be constant with the change of pressboard MC. Similar results could be observed for $\tan \delta$ results.

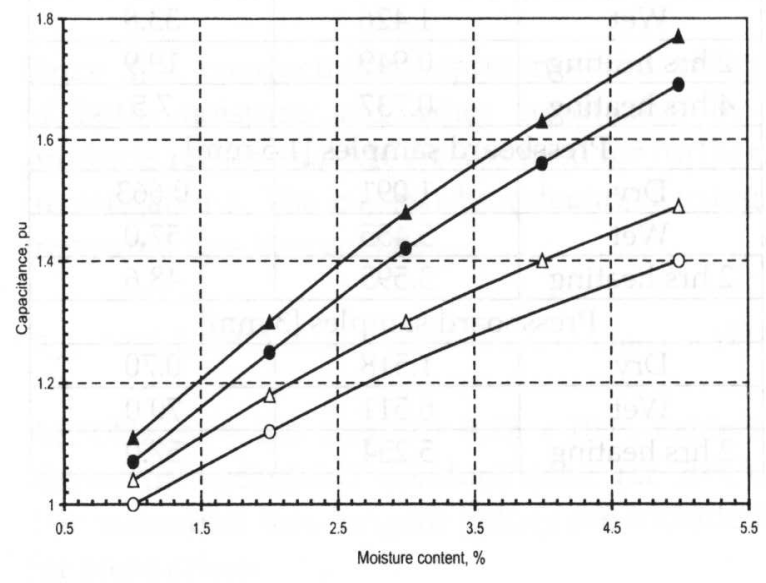

Figure 3(a) - Normalized capacitance of combined insulation as a function of pressboard MC and different insulation geometry 
$X=20 \%, Y=15 \%$

$\triangle X=30 \%, Y=15 \%$

$X=20 \%, Y=25 \%$

$\Delta \mathrm{X}=30 \%, \mathrm{Y}=25 \%$

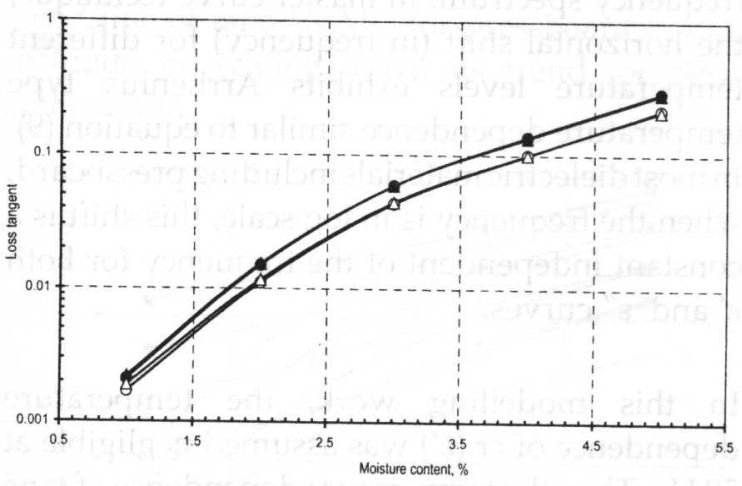

Figure 3(b) - Loss tangent of combined insulation as a function of pressboard MC and different insulation geometry

$X=20 \%, Y=15 \%$

$\triangle X=30 \%, Y=15 \%$

$X=20 \%, Y=25 \%$

$\Delta \mathrm{X}=30 \%, \mathrm{Y}=25 \%$

This geometry dependence can be explained as follows. According to Figure 1c, the oil and pressboard barriers act as series capacitors where the oil equivalent capacitance is much smaller than that of pressboard and therefore is dominating. Since $\mathrm{\varepsilon r}$ of oil is almost constant with moisture, variation of resultant capacitance is not significant. The oil/barrier and spacer/ barrier act as parallel capacitors and both contribute significantly towards the measured capacitance of transformer. Since the $\varepsilon_{r}$ of spacers increases with MC, see Figure 2, the final measured capacitance change significantly with the change of spacer ratio $Y$. In the following study, the geometry was assumed to be fixed and was restricted to case 1 , i.e. $X=20 \%, Y=25 \%$.

\subsection{Effect of Moisture in Paper}

Out of paper and pressboard, the paper insulation can be easily deteriorated as high temperature in windings cause thermal degradation faster and the contaminated oil diffuses moisture quicker. The effect of paper MC was separately analysed by changing the $\mathrm{MC}$ level up to $3 \%$ using extrapolation of curves in Figure 2. However it was found that the influence of paper MC on $\tan \delta$ and capacitance of combined insulation was negligible. As far as the dimensions of a transformer is concerned, the thickness of the paper ( $t$ ) is negligible (high capacitance) compared to pressboard insulation so that the $\tan \delta$ and capacitance value of transformer mainly reflects the MC in pressboard.

\subsection{Effect of Oil Conductivity}

Different $\sigma_{\text {oil }}$ levels were selected from the results in Table 2. Figure 4 shows the calculated $\tan \delta$ and capacitance values for combined insulation at room temperature for different MCs of pressboard. The trend line of $\tan \delta$ for pressboard insulation is also included for comparison. The dependence of capacitance vs MC in pressboard on $\sigma_{\text {oil }}$ was found as very small and one conductivity level has been included.

Since the $\tan \delta$ of the combined insulation is a function of both pressboard MC and $\sigma_{\text {oil }}$ it is convenient to discuss the results in three different 'wetness' levels.

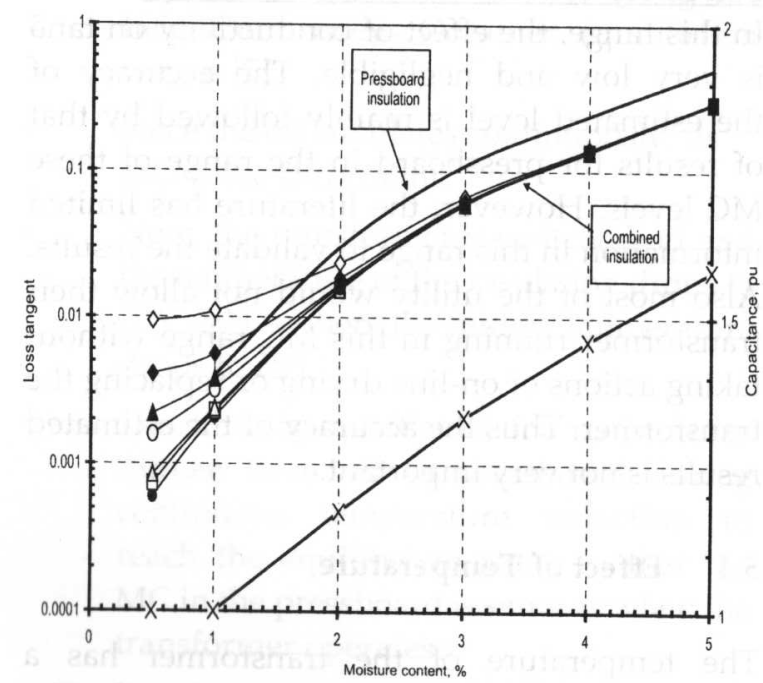

Figure 4 - $\tan \delta$ and normalized capacitance of combined transformer insulation as a function of pressboard MC and oil conductivity

Sample 1, $\square$ Sample 2, $\triangle$ Sample 3, O Sample $4, \diamond$ Sample 5, $\bullet$ Sample 6, $\Delta$ Sample 7, X Capacitance

\section{Dry insulation ( $\mathrm{MC}<2 \%$ ):}

According to Figure 4, the $\sigma_{\text {oil }}$ brings uncertainty of estimating $\mathrm{MC}$ of pressboard from the measured transformer $\tan \delta$ value. At $0.5 \%$ of $\mathrm{MC}$ level i.e. very dry insulation, extremely wetted oil has contributed more than 10 times to the overall $\tan \delta$ value. So, the estimation is unreliable unless the information about the $\sigma_{\text {oil }}$ is precisely known. However, one could argue that since the dry transformers are in good condition in the range the exact values of $\mathrm{MC}$ of pressboard is not very important. So, $\tan \delta$ measurements can still be useable for rough estimation on pressboard 'wetness' in this range of MC levels. 
Wet insulation $(2 \%<\mathrm{MC}<4 \%)$ :

The region of $\mathrm{MC}$ level is highly concerned by the utility. According to Figure 4, it can be clearly seen that the $\sigma_{\text {oil }}$ has limited contribution towards the measured transformer $\tan \delta$ value. The 'wetness' of the pressboard dominates the $\tan \delta$ value and the behaviour is dominant when coming closer to the upper limit of $\mathrm{MC}$. The trend line between tan $\delta$ and MC for pure pressboard validates these findings. Therefore one could make a judgment on the 'wetness' of the insulation by $\tan \delta$ measurements. If the history of the tan $\delta$ values of the transformer is known the reliability of estimation increases further.

\section{Extremely wet insulation (MC > $4.5 \%$ ):}

In this range, the effect of conductivity on $\tan \delta$ is very low and negligible. The accuracy of the estimated level is mainly followed by that of results for pressboard in the range of these MC levels. However, the literature has limited information in this range to validate the results. Also most of the utility would not allow their transformer running in this $\mathrm{MC}$ range without taking actions of on-line drying or replacing the transformer. Thus the accuracy of the estimated results is not very important.

\subsection{Effect of Temperature}

The temperature of the transformer has a significant effect on $\tan \delta$ values $[6,8]$. The temperature of windings may increase up to even $70-90^{\circ} \mathrm{C}$ depending on loading conditions. When a transformer is switched off for its regular maintenance/tests, the temperature drops with the time initially at a higher rate. Thus the modelling work was extended to see the effect of temperature on $\tan \delta$ measurements. With the change of temperature, both the $\sigma_{\text {oil }}$ and $\tan \delta$ of pressboard vary significantly. The temperature dependence of $\sigma_{\text {oil }}$ is given by Arrhenius equation as in Equation (9).

$\sigma=\sigma_{0} e^{\left(-\frac{E_{d c}}{K T}\right)}$

The Edc, T, K, and $\sigma_{0}$ are activation energy, absolute temperature, the Boltzmann constant and pre-exponential factor respectively. The calculation of temperature dependence of $\tan \delta$ of pressboard is not straightforward as that of oil, but one could use master curve technique
[12] applied to dielectric measurements (complex capacitance, i.e. $\mathrm{C}_{0}\left(\varepsilon^{\prime}+\mathrm{j} \varepsilon^{\prime \prime}\right)$ ) over a wider frequency spectrum. In master curve technique, the horizontal shift (in frequency) for different temperature levels exhibits Arrhenius type temperature dependence similar to equation (9). In most dielectric materials including pressboard, when the frequency is in log scale, this shift is a constant independent of the frequency for both $\varepsilon^{\prime}$ and $\varepsilon^{\prime \prime}$ curves.

In this modelling work, the temperature dependence of $\varepsilon r\left(\varepsilon^{\prime}\right)$ was assumed negligible at $50 \mathrm{~Hz}$. Then the temperature dependence of $\tan \delta$ which is only described by the effect of $\varepsilon^{\prime \prime}$, can be calculated by using the horizontal shift of $\tan \delta$ vs frequency curves at different temperatures according to equation (10).

$\Delta \tan \delta \approx m \frac{E_{a}}{K}\left(\frac{1}{T_{2}}-\frac{1}{T_{1}}\right)$

The $\mathrm{m}$ is the approximate gradient of $\tan \delta \mathrm{vs}$ frequency curves around $50 \mathrm{~Hz}$.

In this work, the temperature dependent $\tan \delta$ values were estimated for different temperature levels of $30^{\circ} \mathrm{C}, 40^{\circ} \mathrm{C}$ and $50^{\circ} \mathrm{C}$ by considering $20^{\circ} \mathrm{C}$ as the base values. The approximate gradient values were extracted from the results of frequency and temperature dependent complex capacitance graphs in [13]. Ekanayake in [13], has presented the frequency dependent (from 1 $\mathrm{kHz}$ to $0.1 \mathrm{mHz}$ ) complex capacitance $\left(\varepsilon^{\prime}\right.$ and $\left.\varepsilon^{\prime \prime}\right)$ curves for pressboard samples having different MC levels ( $1 \%-4 \%)$ at different temperature levels $\left(20^{\circ} \mathrm{C}, 50^{\circ} \mathrm{C}\right.$ and $\left.80^{\circ} \mathrm{C}\right)$. By using those curves, the gradient, $\mathrm{m}$ values were estimated for different MC levels $(1 \%-4 \%)$ and different temperatures levels $\left(30^{\circ} \mathrm{C}, 40^{\circ} \mathrm{C}\right.$ and $\left.50^{\circ} \mathrm{C}\right)$. The results are shown in Table 5 .

Table 5 - Estimated gradient values for equation (10) according to [13]

\begin{tabular}{ccccc}
\hline $\begin{array}{c}\text { Temperature } \\
{\left[{ }^{\circ} \mathrm{C}\right]}\end{array}$ & \multicolumn{4}{c}{$\begin{array}{c}\text { Moisture content of pressboard } \\
{[\%]}\end{array}$} \\
\cline { 2 - 5 } & 1.0 & 2.0 & 3.0 & 4.0 \\
\hline 30 & 0.1 & 0.15 & 0.1 & 0.25 \\
40 & 0.15 & 0.3 & 0.2 & 0.5 \\
50 & 0.25 & 0.5 & 0.3 & 0.8 \\
\hline
\end{tabular}

The temperature dependent $\tan \delta$ of combined transformer insulation was obtained by considering the effects of oil and pressboard. Two conductivity levels were used to cover the 
extreme ends of virgin oil $(3.86 \mathrm{pS} / \mathrm{m})$ and nonaged wetted oil $(100.86 \mathrm{pS} / \mathrm{m})$. The obtained results are shown in Figure 5. The comparative trend line of $\tan \delta \mathrm{Vs} \mathrm{MC}$ for pressboard is also included by scaling down its trend for clear comparison.

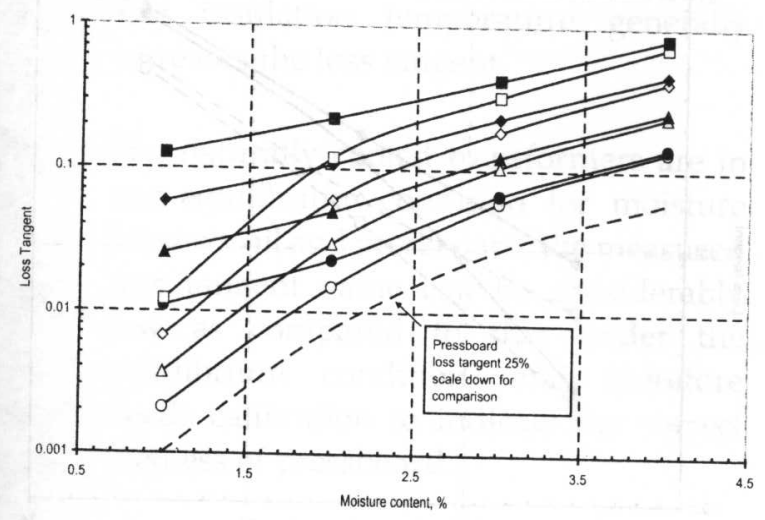

Figure 5 - $\tan \delta$ of combined transformer insulation as a function of pressboard MC, oil $\sigma$ and T.
O At $20^{\circ} \mathrm{C}$ (virgin)

$\triangle$ At $30^{\circ} \mathrm{C}$ (virgin)

$\diamond$ At $40^{\circ} \mathrm{C}$ (virgin)

At $50^{\circ} \mathrm{C}$ (virgin)

- At $20^{\circ} \mathrm{C}$ (wetted)

- At $30^{\circ} \mathrm{C}$ (wetted)

- At $40^{\circ} \mathrm{C}$ (wetted)

- At $50^{\circ} \mathrm{C}$ (wetted)
The $\tan \delta$ of combined insulation always increases with elevated temperature due to the fact that the $\sigma_{\text {oil }}$ and MC of pressboard raise the losses of the insulation with temperature. The behaviour follows the trend line for virgin oil. From the results it is clear that the oil temperature is an essential parameter to determine the MC of pressboard.

\section{Practical considerations}

The above modelled results on $\tan \delta$ measurements are mainly valid if the moisture diffusion is in equilibrium state between oil and pressboard. However, when a transformer is naturally cooled, the moisture starts to diffuse from oil to pressboard, but in most cases of field tests, the diffusion may only start and is far from reaching to the equilibrium condition because of the temperature reduction. For example for $1 \mathrm{~mm}$ thick pressboard, the time taken to reach the equilibrium state will be up to two weeks at $20^{\circ} \mathrm{C}$ [5]. In addition, the elevated temperature along the height of the transformer from bottom to top also affects different levels of moisture distribution between pressboard and oil. These two factors, the most probable effective nonequilibrium conditions appearing during natural cooling, may influence the accuracy of using $\tan \delta$ measurements to estimate the moisture level.

As a case study, the effect of non-equilibrium state and temperature variation has been superimposed to the analysed data in part 5 . The following assumptions are made on the analysis:

-Initially the transformer operates for a long time. Despite the daily changing operating cycles, it is in the equilibrium state for moisture diffusion. The temperature variation along the height of the insulation is $40^{\circ} \mathrm{C}-70^{\circ} \mathrm{C}$ where the middle temperature is $55^{\circ} \mathrm{C}$.

- The MC of pressboard varies along the height and obeys Oommen equilibrium curves [5].

- $\quad$ Since the oil circulates continuously, its $\mathrm{MC}$ value is constant.

- Now, the transformer is switched off and the temperature of the insulation drops to $20^{\circ} \mathrm{C}-30^{\circ} \mathrm{C}$, where the middle temperature drops to $25^{\circ} \mathrm{C}$.

- The time is insufficient for moisture to diffuse from oil to pressboard during continuous temperature reduction to reach the equilibrium state, so that the $\mathrm{MC}$ in the pressboard is same as when the transformer operates.

The height of the transformer was divided into seven parts. The tan $\delta$ of each part was estimated and the overall $\tan \delta$ was estimated by treating them as seven capacitors connected in parallel. In the equilibrium state, the temperature varied in each part as $40^{\circ} \mathrm{C}, 45^{\circ} \mathrm{C}, 50^{\circ} \mathrm{C}, 55^{\circ} \mathrm{C}, 60^{\circ} \mathrm{C}, 65^{\circ} \mathrm{C}$ and $70^{\circ} \mathrm{C}$. Three levels of MCs in pressboard were used as $1 \%, 2 \%$ and $3 \%$ which appeared in the middle height of the insulation. The MC values in the other six parts (except the middle) were calculated using equilibrium curves [5].

When the temperature drops to $20-30^{\circ} \mathrm{C}$, the $\tan \delta$ of pressboard in each segment was calculated using Figure 5. The tan $\delta$ of oil was estimated using the temperature dependent conductivity (eqv (1) and (9)). Two cases were considered as non-aged and aged oil to represent the extreme ends of oil conductivity. Then the resultant $\tan \delta$ values were estimated for the combined insulation at different $\mathrm{MCl}$ levels of the pressboard i.e. the average value appearing in the middle of the transformer. 
Figure 6 shows the variation of estimated $\tan \delta$ values. The corresponding $\tan \delta$ results for equilibrium state are used for the comparison. As expected, the $\tan \delta$ values at non-equilibrium state are lower than that of equilibrium state confirming the moisture appears mainly in oil. Further the relationship between measurabletan $\delta$ values (non-equilibrium) and modelled results (equilibrium) was established and it has been found that the relationship can be approximated to a linear behaviour. So, the approximate $\tan \delta$ value at equilibrium state can be determined by increasing about $60 \%$ to that of non-equilibrium state. This relationship is nearly valid for both aged and non-aged oils.

As a summery, by using the above established relationships, the following general guidelines can be given to estimate MC of the insulation from the measurement of loss tangent across LV and $\mathrm{HV}$ windings of the transformer.

The marginal level of $\mathrm{MC}$ in the pressboard insulation is $2 \%$ and periodic measurements (at least annually for transformers with longer service period) will help to see the tendency of moisture development.

If a transformer is allowed to cool naturally for a sufficient period to achieve the equilibrium condition i.e. couple of days, and if the $\tan \delta$ measurement is done at room temperature, the effect of temperature and non-equilibrium conditions can be eliminated. Thus rough estimation of MC level of insulation can be obtained from the results established in Figure 4. For lower MC levels additional tan $\delta$ measurement is required from an oil sample collected from the same transformer at room temperature.

During regular maintenance period, if the duration lasts only several hours, still rough estimation of MC level can be achieved by taking the measurements when temperature reaches closer to the room temperature. Since this situation is under non-equilibrium state, calibration is necessary to predict for that under equilibrium condition. i.e. see Figure 6.

One of the challenges that utility facing is the lack of information on the geometry of old transformers. The figures are given for typical power transformer i.e. $X=20 \%$ and $Y=25 \%$. Since $\mathrm{Y}$ is the dominant part affecting the $\tan \delta$ value and at the same time, analysis were done at the upper limit of $Y$, for other cases, the estimated MC values may be slightly above the actual values, see the Figure 3 . On the other hand, the $X$ value has a limited effect on the estimated results of $\mathrm{MC}$.

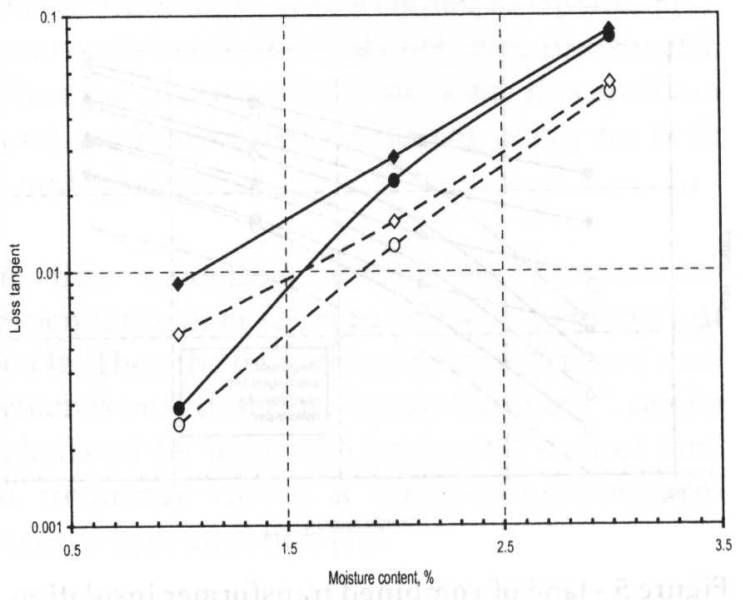

Figure $6-\tan \delta$ as a function of pressboard MC under equilibrium and non-equilibrium conditions

O Non-equilibrium state for non-aged oil

- Equilibrium state for non-aged oil

$\diamond$ Non-equilibrium state for aged oil

- Equilibrium state for aged oil

\section{Conclusions}

The moisture content in the paper and pressboard increases as the result of insulation ageing in a power transformer. For an in-service transformer which gradually approaches its end of designed life, the measured loss tangent of the transformer can be used as a diagnostic tool to indicate the 'wetness' of the insulation. However, the other factors such as insulation geometry, oil conductivity, insulation temperature and state of moisture equilibrium between oil and pressboard are also contributed towards the loss tangent result and a necessity arises to rectify these effects:

- Out of paper and pressboard, the moisture in pressboard is the dominating part contributing to the increase of loss tangent measurement which directly expresses the 'wetness' of the insulation.

- The amount of pressboard spacers strongly affects the rate of the increase of loss tangent and capacitance with moisture content, whereas the amount of pressboard barriers has a constant increment. 
- The oil conductivity affects the loss tangent when the transformer is in dry condition whereas under wet and extremely wet conditions, pressboard moisture dominates the result.

- The insulation temperature generally increases the loss tangent.

- The naturally cooled transformers are in non-equilibrium condition for moisture between oil and pressboard, the measured loss tangent value can be considerably low as compared to that under the equilibrium condition, and therefore needs calibration to indicate the correct wetness of pressboard.

It can be concluded that for a transformer with the insulation geometry fixed to $X=20 \%$ and $Y=25 \%$, at the room temperature and under equilibrium condition, the measured loss tangent value of $2 \%$ and above indicate that the transformer is wet. If any of the fixed factors deviates, one can still use the measured loss tangent as a diagnostic tool if proper calibration is carried out according to the established relationships.

\section{References}

1. IEEE std.62-1995, IEEE guide for diagnostic field testing of electric power apparatus - part 1: oil filled power transformers, regulators, and reactors, 1995.

2. Saha, T.K., "Review of modern diagnostic techniques for assessing insulation condition in aged transformers", IEEE Trans. on DEI, Vol. 10, No. 5, pp. 903-917, October 2003.

3. Wang, M., \& Vandermaar, A.J., "Review of condition assessment of power transformers in service", IEEE EI magazine, Vol. 18. No. 6, pp. 12-25, Nov/Dec 2002,

4. Van Bolhuis, J.P., Gulski, E., \& Smit, J.J., "Monitoring and diagnostic of transformer solid insulation", IEEE Trans. on PD, Vol. 17, No. 2, pp. 528-536, April 2002,

5. Du, Y., Zahn, M., Lesieutre, B.C., Mamishev, A.V., \& Lindgren S.R., "Moisture equilibrium in transformer paper-oil systems", IEEE Trans. EI Magazine, Vol. 15, No. 1, pp. 11-20, 1999.
6. Du, Y., Marnishev, A.V., Lesieutre, B.C., Zahn, M., \& Kang. S.H., "Moisture solubility for differently conditioned transformer oil" IEEE Trans on DEI, Vol. 8, No. 5, pp. 805-811, 2001.

7. Gubanski, S.M., Blennow, J., Karlsson, L., Feser, K., Tenbohlen, S., Neumann, C., MoscickaGrzesiak, H., Filipowski, A., \& Tatarski, L., "Reliable diagnostics of $\mathrm{HV}$ transformer insulation for safety assurance of power transmission system, Rediotool - a European research project", Cigre 2006, paper D1-207.

8. Brown, M.A., Dodd, S.J., Ahern, B., Pettinger, J., \& Waite F., "Dielectric response of SRBP as a function of oil and oil/moisture absorption", Proc. CEIDP, USA, pp. 736-739, Oct. 2006.

9. Sokolov. V., Bulgakova, V., \& Berier, Z., "Assessment of power transformer insulation condition", Proc. EL conf. and EM and coil winding conf. 2001, pp. 605-613.

10. Gafvet, U., Frimpong, G., and Fuhr, J, "Modelling of dielectric measurements on power transformers", in Proc. $37^{\text {th }}$ Session Large High Voltage Electric Systems (Cigre):b Group 15 - Materials for Electrotechnology, paper 103, Paris, France, 1998.

11. In communication with John Lapworth, Double Powertest, UK, 2007

12. Jonscher A. K., Dielectric relaxation in solids, 2nd ed., Chelsea Dielectrics Press LtD, UK, 1996.

13. Ekanayake, C.M.B., Diagnosis of moisture in transformer insulation - application of frequency domain spectroscopy, PhD thesis, Chalmers University of Technology, 2006.

\section{Acknowledgement}

The author would like to express his gratitude to University of Manchester for providing the assistance to conduct this study and Dr. ZD Wang for her engagement in commenting and discussing this work. The financial support given by commonwealth scholarship commission, UK, is also acknowledged. 